Note: This is a post-peer-review, pre-copyedited version of an article published in a revised form in European Journal of Risk Regulation [http://doi.org/10.1017/err.2021.28]. This version is published under a Creative Commons CC-BY-NC-ND. No commercial re-distribution or reuse allowed. Derivative works cannot be distributed. (C) The Author(s), 2021. Published by Cambridge University Press.

\title{
Autonomous artificial intelligence and uncontemplated hazards: towards the optimal regulatory framework
}

\author{
Mitja Kovac \\ University of Ljubljana School of Economics and Business, Slovenia \\ Kardeljeva pl.17, 1000 Ljubljana, Mitja.kovac@ef.uni-lj.si
}

\begin{abstract}
:
The issue of super-intelligent AI has started to attract ever more attention in economics, law, sociology and philosophy studies. A new industrial revolution is being unleashed and it is vital that lawmakers address the systemic challenges it is bringing while regulating its economic and social consequences. The current trends towards developing super-intelligent machines able to interact, learn and take autonomous decisions urgently call for substantive regulatory treatment. This paper sets out recommendations to ensure optimal regulatory intervention covering potential, uncontemplated AI-related risks. If it evolves in ways unintended by its designers, judgment-proof super-intelligent AI could create unforeseeable losses wherever current tort and contract law regimes do not ensure optimal risk internalisation and precaution, while also deterring opportunism. Here, the governing maxim should be optimal design timing with the anticipatory regulatory principle for potential unforeseeable losses and uncontemplated risks. Moreover, the paper argues that, due to identified shortcomings, the debate on the different approaches to controlling hazardous activities boils down to a question of efficient ex ante safety regulation. Finally, it is suggested that it is better to place autonomous AI in the existing legal categories and to not create a new electronic legal personality.
\end{abstract}

JEL classification: C23, C26, C51, K42, O43

Keywords: Autonomous artificial intelligence, liability, risk, judgment-poof problem, regulatory design timing 


\section{Introduction}

Super-intelligent artificial intelligence and recent breakthroughs in machine-human interactions and machine learning technology are affecting ever more aspects of our lives. It is exponentially growing and certain of its materialisations bring a greater threat to privacy, are ethically questionable and possibly even dangerous, risky and harmful. ${ }^{1}$ The creation of autonomous, non-natural artificial super-intelligence able to make choices via an evaluative process is one of the most pressing questions in the world today. Namely, super-intelligent artificial intelligence (hereinafter $\mathrm{AI}$ ) is unleashing a new industrial revolution and it is vital that lawmakers systemically address its challenges and regulate its economic and social effects, while not stifling innovation. Current trends towards developing super-intelligent machines that are able to interact, learn and take autonomous decisions also raise a variety of concerns regarding the potential for their direct/indirect harmful effects which call for substantive legal and economic consideration.

Russel, for example, argues that no one can predict exactly how the new AI technology will develop but, if autonomous machines start to far exceed our thinking capacity and we leave this issue unaddressed, AI could well be the last event in human history. ${ }^{2}$ He suggests that poorly designed super-intelligent machines might pose a serious risk to humanity. Moreover, Turner argues that Europeans have not come to grips with what is ethical, let alone with what the law should be, creating a growing legal vacuum in almost every domain touched by this unprecedented technological "development."3 Similarly, Buyers suggests that lawyers are currently flummoxed what happens when a self-driving car has a software failure and hits a pedestrian, or a drone's camera happens to catch someone skinny-dipping in a pool or taking a shower, or a robot kills a human in self-defence. ${ }^{4}$ Further, Teubner convincingly shows that autonomous AI agents may actually pose three new liability risks: a) autonomy risk, stemming from stand-alone 'decisions' taken by the AI agents; b) association risk, arising from the close cooperation between people and AI agents; and c) network risk that occurs when computer

\footnotetext{
${ }^{1}$ M Kosinski and Y Wang, "Deep Neural Networks are more Accurate than Humans at Detecting Sexual Orientation from Facial Images" (2018) 114(2) Journal of Personality and Social Psychology 246-257.

${ }^{2}$ S Russell, Human Compatible: Artificial Intelligence and the Problem of Control (Allen Lane-, 2019) 4. On the use of AI in producing new intellectual creations, see e.g. M Degli Esposti, F Lagioia and G Sartor, "The Use of Copyrighted Works by AI Systems: Art Works in the Data Mill"(2019) 11(1) European Journal of Risk Regulation 51-69. Also see S Russel and P Norvig, Artificial Intelligence: A Modern Approach (3 ${ }^{\text {rd }}$. ed., Harlow: Pearson 2016).

${ }^{3}$ J Turner, Robot Rules: Regulating Artificial Intelligence (Palgrave Macmillan 2019) 81-86.

${ }^{4}$ J Buyers, Artificial Intelligence: The Practical Legal Issues (Law Brief Publishing 2018) 21-35.
} 
systems are close integrated with other computer systems. ${ }^{5}$ In addition, super-intelligent AI might lead to serious indirect or direct harm. For example, high-speed trading algorithms that could destabilise the stock market or cognitive radio systems that might interfere in emergency communications, may, either alone or in combination, cause serious damage.

Given such developments, many lawmakers around the globe have started on intensive lawmaking activity ${ }^{6}$ with respect to the issue of liability and other broader challenges brought by emerging digital technologies. For example, the EU Commission established a special expert group on liability made up of the "Product Liability Directive" formation and the "new technologies" formation. ${ }^{7}$ These two expert groups have also been given the task of determining whether regulatory intervention on $\mathrm{AI}$ technologies is appropriate and necessary and, if so, if such an intervention should be developed in a horizontal or sectoral way. ${ }^{8}$

From the law and economics perspective, the role of a civil liability system is to deter people and firms from injuring others, deter and prevent risks, internalise the costs of risky events and compensate those who are injured. In addition, one may wonder whether society's aims would be better served by more radically reformulating our relationship with superintelligent $\mathrm{AI}$ and if the current rules indeed exhaustively cover all of the risks that might arise from super-intelligent AI.

By incorporating the main insights from the tort law and economics literature ${ }^{9}$, this paper seeks to address the role of public policy in regulating super-intelligent AI and the related civil liability for damage it may cause . Despite the possibility of super-intelligent AI causing

\footnotetext{
${ }^{5}$ G Teubner, "Digital Personhood? The Status of Autonomous Software Agents in Private Law" (2018) Ancilla Iuris.

${ }^{6}$ See e.g. Resolution on the Civil Law Rules on Robotics of the European Parliament, P8-TA (2017)0051.

${ }^{7}$ EU Commission, COM (2018) 237 final.

${ }^{8}$ EU Commission, COM (2018) 237 final.

${ }^{9}$ See e.g. A Galasso and H Luo, "Punishing Robots: Issues in the Economics of Tort Liability and Innovation in Artificial Intelligence," in NBER Chapters, The Economics of Artificial Intelligence: An Agenda(National Bureau of Economic Research 2018) p 493-504; H B Schäfer and C Ott, The Economic Analysis of Civil Law (Edward Elgar 2004) p 107-273; M Faure, "Toward a Harmonized Tort Law in Europe? An Economic Perspective" (2001) 8 Maastricht Journal of European and Comparative Law 4, 339-350; H B Schäfer, "Tort Law: General" in B Bouckaert and G De Geest (eds.), Encyclopedia of Law and Economics (Edward Elgar 2000) p 569-596; W Emons and J Sobel, "On the Effectiveness of Liability Rules when Agents are not Identical"(1991) 58 Review of Economic Studies, 375-390; S Shavell, Economic Analysis of Accident Law (Harvard University Press 1987); A M Polinsky and W P Rogerson, "Product Liability, Consumer Misperceptions and Market Power"(1983) 14 Bell Journal of Economics, 581-589; S Shavell, "Strict Liability versus Negligence"(1980) 9 Journal of Legal Studies, 1-25; J K Arrow, "Optimal Insurance and Generalized Deductibles" (1974) 1 Scandinavian Actuarial Journal, 1-42; R A Posner, "A Theory of Negligence" (1972) 1 Journal of Legal Studies, 29-96; R A Posner, "Strict Liability: A Comment"(1973) 2 Journal of Legal Studies 1, 205-221; G Calabresi, "Some Thoughts on Risk Distribution and the Law of Torts"(1961) 70 Yale Law Journal 4, 499-553; G Calabresi, "The Decision for Accidents: An Approach to Non-fault Allocation of Costs" (1965) 78 Harvard Law Review 4, 713-745; G Calabresi, The Costs of Accidents: A Legal and Economic Analysis (Yale University Press 1970).
} 
harm to others, no incentives to ensure safety stem from the typical human-centred tort law system as enforced with monetary sanctions. This phenomenon is known in the law and economics literature as a "judgment-proof problem" and a standard argument in law-making discussions on operationalising policies, doctrines and rules. ${ }^{10}$ The law and economics literature on the judgment-poof problem is vast and explores the effects, extent and potential remedies to this unwelcome arrival in the liability system. ${ }^{11}$

This paper relies on law and economics insights into the judgment-proof problem ${ }^{12}$ with respect to autonomous artificial intelligence to offer several recommendations for an improved, Europe-wide, regulatory intervention for deterring hazardous risks and inducing optimal precaution.

The paper also contributes to the literature by highlighting the practical and theoretical importance of the super-intelligent-AI-related judgment-proof problem. According to the classic definition, a person is "judgment-proof" when they are financially insolvent or whose income and assets are not available to satisfy a judgment. However, this paper employs a broad judgment-proof definition that also includes the problem of low incentive to reduce risk that arises when a person is completely indifferent to both the ex ante possibility of being found legally liable for harm done to others and potential accident liability (since no sanction is expected). It must be stressed that this problem of diluted incentives (a broad judgment-proof definition) is distinct from what scholars and practitioners often call a "judgment-proof problem" generally described as when an tortfeasor is unable to pay for all the losses, leaving the victim without full compensation. ${ }^{13}$ This broadly-defined judgment-proofness means that super-intelligent AI could be responsible for substantial harm and unprecedented hazards that the current liability-related tort law regimes have failed to ensure optimal risk internalisation, precaution and deter hazards.

The analysis presented here is both positive and normative. The analytical approach employs inter-disciplinary analysis enriched with concepts used in the economic analysis of law. ${ }^{14}$ To

\footnotetext{
${ }^{10}$ S Shavell, "The Judgement Proof Problem" (1986) 6 International Review of Law and Economics 1, 45-58.

${ }^{11}$ See e.g. J J Ganuza and F Gomez, "Being Soft on Tort. Optimal Negligence Rule under Limited Liability”(2005) UPF Working paper; J Boyd and D E Ingberman, "Noncompensatory Damages and Potential Insolvency" (1994) 23 Journal of Legal Studies 2, 895-910.

${ }^{12}$ Shavell, supra, note 10 .

${ }^{13}$ See e.g. G Huberman D Mayers and C W Smith, “Optimal Insurance Policy Indemnity Schedules.” (1983) 14 Bell Journal of Economics 2, 415-426; and W R Keeton and E Kwerel. 1984. "Externalities in Automobile Insurance and the Underinsured Driver Problem" (1984) 27 Journal of Law and Economics 1, 149-179.

${ }^{14}$ See G De Geest, Contract Law and Economics - Encyclopedia of Law and Economics (Volume 6, 2nd ed., Edward Elgar 2011); and R A Posner, Economic Analysis of Law (9th ed., Wolters Kluwer Law Publishers, 2014).
} 
make the economic analysis more accessible to readers unacquainted with sophisticated mathematical reasoning, the law and economics toolkit employed follows the classical law and economics approach. ${ }^{15}$

However, several caveats should be issued. Namely, the limited scope of the paper considers the narrow fields of tort and product liability law while omitting analysis of consumer protection and antitrust law. It solely focuses on what might be called hypothetical, superintelligent AI which autonomously learns from its own mixed experience and interacts with its environment in unique and unforeseeable ways.

This paper is structured as follows. The first part presents the general background, several definitions and provides a manual for the field of AI's development and deployment. In the second part, key questions for AI policy are considered. These include the use of force, liability, safety and certification. Moreover, crucial questions imposed by the lawmaker are described along with three critical fields of application. In part three, the paper provides several recommendations for optimal regulatory intervention. While applying tort law and economics insights into the judgment-proof problem to artificial intelligence, this part also offers several economically-inspired, instrumental insights for an improved liability law regime. Finally, some conclusions are presented.

\section{General background, key concepts and European Union policy initiative}

It is clear that humankind faces the prospect of ever more sophisticated super-intelligent AI unleashing a new industrial revolution that will profoundly alter and transform all of society or at least huge swathes of it. While some marvel at the capacity of artificial intelligence ${ }^{16}$, others seem to be more concerned that our species will have a mortal struggle with super-powerful AI that will ultimately prove to be humankind's "final invention". ${ }^{17}$ Barrat, for instance, adds that artificial intelligence is indeed helping people choose which books you buy, which movies to see, it is the 'smart' in smartphone, will soon drive our cars, is making most of the trades on Wall Street, and controlling vital energy, water and transport infrastructure. ${ }^{18}$ However,

\footnotetext{
${ }^{15} \mathrm{R}$ Van der Bergh, The Roundabouts of European Law and Economics (Eleven International Publishing 2018), p 21-28.

${ }^{16}$ C Metz, "In a Huge Breakthrough, Google's AI Beats a Top Player at the Game of Go" (2016) Wired.

${ }^{17}$ See e.g. J Barrat, Our Final Invention: Artificial Intelligence and the End of Human Era (Thomas Dunes Books 2013); Russel, supra, note 2.

${ }^{18}$ Ibid.
} 
artificial intelligence combined with robotic systems is accomplishing tasks in ways that cannot be anticipated in advance, while robots make the line between person and instrument ever blurrier. $^{19}$

\subsection{Setting the scene: definitions, concepts and research trends}

Curiously, there is no precise, straightforward, universally-accepted definition of artificial intelligence (AI), even a consensus definition. Calo, for example, argues that $\mathrm{AI}$ is best understood as a set of techniques aimed at approximating some aspect of human or animal cognition using machines. ${ }^{20}$ This paper employs a more useful definition given by Nilsson, which defines AI as: "Artificial intelligence is that activity devoted to making machines intelligent, and intelligence is that quality that enables an entity to function appropriately and with foresight in its environment". ${ }^{21}$ Moreover, in this paper the term artificial intelligence denotes autonomous artificial intelligence that is independent and has the capacity to self-learn, interact, take autonomous decisions, develop emergent properties and adapt its behaviour/actions to the environment and has no life in a biological sense.

However, in recent years the field of AI has seen a shift from simply building systems that are intelligent to building intelligent systems which are human-aware and trustworthy. ${ }^{22} \mathrm{~A}$ set of techniques known as "machine learning", partly supported by cloud computing resources and widespread, Web-based data gathering have in particular propelled the field and been the main source of excitement. Machine learning (hereinafter ML) refers to a system's capacity to improve its performance in a task over time. ${ }^{23}$ These days, ML is divided into two main branches: a) unsupervised ML (involving matrix factorisation, regularisation and neuro-

\footnotetext{
${ }^{19}$ R Calo, "Robotics and the Lessons of Cyber Law" (2015) 103 California Law Review 102, 513-63.

${ }^{20}$ R Calo, "Robots as Legal Metaphors" (2016) 30 Harvard Journal of Law \& Technology 1, 209-37; and R Calo, "Artificial Intelligence Policy: A Primer and Roadmap" (2017) 51 UC Davis Law Review, 399-435.

${ }^{21} \mathrm{~J}$ N Nilsson, The Quest for Artificial Intelligence: A History of Ideas and Achievements (Cambridge University Press 2010).

${ }^{22}$ See J Kaplan, Artificial Intelligence: What Everyone needs to Know (Oxford University Press 2016); P Stone, R Brooks, E Brynjolfsson, R Calo, O Etzioni, G Hager, J Hirschberg, S Kalyanakrishnan, E Kamar, S Kraus, K Leyton-Brown, D Parkes, W Press, A Saxenian, J Shah, M Tambe and A Teller, Artificial Intelligence and Life in 2030 (Report of the 2015 study panel 50, Stanford University, 2016); and P McCorduck, Machines who Think: A Personal Inquiry into the History and Prospects of Artificial Intelligence (A.K. Press 2004) 133.

${ }^{23}$ H Surden, "Machine Learning and Law" (2014) 89 Washington Law Review 1, 87.
} 
networks as well as finding clusters of observation similar in terms of their covariates dimensionality reduction.); and b) supervised ML. ${ }^{24}$

Calo notes that ML is strongly driven by "deep learning", a technique (operating within ML) described as a form of "adaptive artificial neural networks trained using a method called backpropagation". ${ }^{25}$ Analytically speaking, deep learning (hereinafter DL) "leverages manylayered structures to extract features from enormous data sets in service of practical tasks requiring pattern recognition, or use other techniques to similar effect". ${ }^{26}$ These trends in ML and DL are now impelling the 'hot' research areas that encompass large-scale-machinelearning, reinforcement learning, robotics, computer vision, natural language processing, collaborative systems, crowdsourcing and human computation, algorithmic game theory and computational social choice, the Internet of Things and neuromorphic computing.

Over the next 15 years, scholars expect a stronger focus on developing systems which are human-aware, meaning that they specifically model, and are specifically designed for, the characteristics of the people with whom they are intended to interact. ${ }^{27}$ Such human-like systems will be able to creatively develop "interactive and scalable ways to teach other robots and to develop human-like characteristics, including decision making, feelings and potential self-awareness". ${ }^{28}$

\subsection{EU legislative initiatives and activity in the field of AI}

In 2017, the EU Parliament urged the EU Commission to propose legislation containing a set of detailed civil law rules on robotics and artificial intelligence. ${ }^{29}$ The European Parliament

\footnotetext{
${ }^{24}$ See S Mullainathan and J. Spiess, "Machine Learning: An Applied Econometric Approach"(2017) 31 Journal of Economic Perspectives 2, 87-106; H R Varian, "Big Data: New Tricks for Econometrics" (2014) 28 The Journal of Economic Perspectives 3, 3-27; and D M Blei, Y Ng and M I Jordan, "Latent Dirichlet Allocation"(2003) 3 Journal of Machine Learning Research 1, 993-1022. Also see S Athey, "The Impact of Machine Learning on Economics" in "The Economics of Artificial Intelligence: An Agenda" (National Bureau of Economic Research 2018);P K Gopalan, J M Hofman and D M Blei, "Scalable Recommendation with Hierarchical Poisson Factorization" (2015) Conference on Uncertainty in Artificial Intelligence, 326-335; and P Gopalan, L Charlin and D M Blei, "Content Based Recommendations with Poisson Factorization" (2014) Advances in Neural Information Processing Systems, 3176- 3184 .

${ }^{25}$ Calo, supra, note 19.

${ }^{26}$ Nat'l Sci. \& Tech. Council, Exec. Office of the President, "Preparing for the Future of Artificial Intelligence" (2016) 6, 9-10.

${ }^{27}$ P Stone, R Brooks, E Brynjolfsson, R Calo, O Etzioni, G Hager, J Hirschberg, S Kalyanakrishnan, E Kamar, S Kraus, K Leyton-Brown, D Parkes, W Press, A Saxenian, J Shah, M Tambe and A Teller, supra, note 22.

${ }^{28}$ Stone et al., supra, note 22. Also see J Pearson, "Uber's AI hub in Pittsburgh Gutted a University Lab - Now it's in Toronto" (2017) Vice Motherboard.

${ }^{29}$ 2015/2103(INL), P8_TA (2017) 0051.
} 
had emphasised that draft legislation was urgently needed to clarify liability issues, especially as concerns self-driving cars, and called for a mandatory insurance scheme and supplementary fund to ensure that victims of accidents involving driverless cars are fully compensated. ${ }^{30}$ It passed a Resolution stating that the "EU should create a specific legal status for robots, so that at least the most sophisticated autonomous robots could be established as having the status of electronic persons responsible for making good any damage they may cause, and possibly applying electronic personality to cases where robots (AI) make autonomous decisions or otherwise interact with third parties independently". 31

In its Communication from the Commission to the European Parliament on artificial intelligence for Europe ${ }^{32}$, the EU Commission informs that "although strict liability for producers of AI is uncontested, the precise effects of new technological developments will have to be more closely analysed". ${ }^{33}$

\section{A synthesis of law and economics scholarship: torts and safety regulation}

As shown above, AI might be able to do much more than merely process information and will come to exert direct control over objects in the human environment. Such super-intelligent AI might hypothetically cause substantial indirect or direct harm. ${ }^{34}$ For instance, Calo argues that high-speed trading algorithms that could destabilise the stock market or cognitive radio systems that could interfere in emergency communications may, either alone or in combination, cause serious damage. ${ }^{35}$ In order to mitigate these possible serious hazards and harm, law-makers may be able to combine ex ante regulatory intervention and the ex post imposition of liability. However, the initial question is: How would a lawmaker seek to modify the behaviour of superintelligent AI? Namely, the self-learning capacity of a super-intelligent AI agent might mean that it is de facto immune from tort law's deterrence capacity and consequential externalisation of the precaution costs. There is a real possibility that, if we do manage to build super-

\footnotetext{
30 2015/2103(INL), P8_TA (2017) 0051.

${ }^{31}$ EU Parliament, Resolution on Civil Law Rules in Robotics (P8_TA (2017) 0051).

${ }^{32}$ EU Commission, Communication from the Commission to the European Parliament on artificial intelligence for Europe, COM (2018) 237 final.

${ }^{33}$ The EU Commission also established the Expert Group on Liability and New Technologies that provides expertise on the applicability of the Product Liability Directive to traditional products, new technologies and new societal challenges (Product Liability Directive formation) and assists the Commission in developing principles that can serve as guidelines for possible adaptations of applicable laws at the EU and national level relating to new technologies (New Technologies formation).

${ }^{34}$ R Calo, "The Case for a Federal Robotics Commission 9-10” (2014) Brookings Centre For Technical Innovation.

35 Ibid.
} 
intelligent AI with some degree of autonomy, our legal system might be unprepared and unable to control it.

This section presents a set of law and economics recommendations to ensure optimal regulatory intervention able to deter hazards and induce optimal precaution while simultaneously keeping dynamic efficiency - incentives to innovate - undistorted.

\subsection{The economic function of tort law}

Tort law defines the conditions in which a person is entitled to compensation for damage if not based on a contractual obligation and encompasses all legal norms that concern the claim made by an injured party against s wrongdoer (tortfeasor). Economically speaking, any "reduction of an individual's utility level caused by a tortious act can be regarded as damage". ${ }^{36}$ The rules of tort law aim to draw a just and fair line between detrimental events that should lead to compensation for damage and others for which the damage should lie where it falls. A thorough overview of the tort law and economics literature exceeds the limits of this paper and is available elsewhere. ${ }^{37}$ However, it should be emphasised that this literature traditionally addresses three broad aspects of tortious liability. The first is assessing its effects on incentives (including incentives to participate in activities and incentives to mitigate the associated risk) - analytically speaking, tort law is thus an instrument that improves the flow of inducements; ${ }^{38}$ the second concerns risk-bearing capacity and insurance; while the third is the related administrative expense entailing the costs of legal services, the value of litigants' time and lost opportunities, and the court operating costs. ${ }^{39}$ The literature also shows that since the administrative and procedural costs of a tort law case can very high, alternative institutions like strict liability or ex ante safety regulation might be more effective at reducing the overall costs of accidents than tort law liability. ${ }^{40}$

\footnotetext{
${ }^{36}$ H B Schäfer, "Tort Law: General", in B Budewijn and G De Geest (eds), Encyclopedia of Law and Economics (Edward Elgar 2000) p 569-596.

${ }^{37}$ See e.g. R Cooter and T Ulen, Law and Economics (6th ed., Addison-Wesley 2016) 287-373; Posner, supra, note 14; H B Schäfer and C Ott, The Economic Analysis of Civil Law (Edward Elgar 2004) 107-273; and E MacKaay, Law and Economics for Civil Law Systems. (Edward Elgar 2015).

${ }^{38}$ G De Geest, "Who should be Immune from Tort Liability" (2012) 41 The Journal of Legal Studies 2,291-319.

${ }^{39}$ S Shavell, "Liability for Accidents" in M A Polinsky and S Shavell (eds.), Handbook of Law and Economics (Volume 1, North-Holland 2007), p 139-183.

${ }^{40}$ D N Dewees, D Duff and M J Trebilcock, Exploring the Domain of Accident Law: Taking the Facts Seriously (Oxford University Press 1996) 452.
} 


\subsection{Liability for harm versus safety regulation}

In his seminal paper on liability for harm versus the regulation of safety, Professor Shavell paved the way to analytical understanding of the optimal employment of tort liability and/or regulatory standards. Shavell instrumentally addressed the effects of liability rules and direct regulation on a rational self-interested party's decision-making process. ${ }^{41}$ Namely, liability in tort and safety regulation are two different approaches to controlling activities that create risks of harm and inducing the optimal amount of precaution. ${ }^{42}$ Yet Shavell stresses that major mistakes have occurred in the use of liability and safety regulation. ${ }^{43}$ Regulation, where applied exclusively, has for various reasons often proven inadequate, whereas due to causation problems tort liability might also provide sub-optimal deterrence incentives. ${ }^{44}$ Shavell adds that regulatory fines are identical to tortious liability in that they create incentives to reduce risks by making parties pay for the harm they cause. ${ }^{45}$ Nevertheless, as Shavell emphasises, regulatory fines have an advantage in instances where private legal claims (and related tortious liability) would not be pursued due to difficulty of establishing causation or where damage is widely dispersed. ${ }^{46}$ In addition, Rose-Ackerman suggests that regulation (statutes) should generally dominate provided agencies are able to employ rule-making to shape policy, ${ }^{47}$ whereas Schmitz argues that the joint use of liability and safety regulation is optimal if wealth varies among injurers. ${ }^{48}$

\subsection{Liability issues and the classic human-centric-judgment-proof problem}

In its original, narrow meaning of the concept human-centric "judgment-proof", the problem refers to the fact that human tortfeasors are unable to pay fully for the harm they may cause, giving them a bigger incentive than otherwise to engage in risky activities. Shavell and Summers coined the term "judgment proof" in their path-breaking article on this problem

\footnotetext{
${ }^{41}$ S Shavell, "Liability for Harm versus Regulation of Safety” (1984) 13 Journal of Legal Studies 2, 357-374.

42 Tort liability is private in nature and works not by social command but indirectly through the deterrent effect of damage actions that may be brought once harm occurs, whereas standards and ex ante regulations are public in character and modify behaviour in an immediate way through requirements that are imposed before the actual occurrence of harm; Shavell, ibid.

${ }^{43}$ Ibid.

${ }^{44}$ Shavell, ibid. Also see R A Epstein, "The Principles of Environmental Protection; The Case of Superfund" (1982) 2 Cato Journal 1, 9-53.

${ }^{45}$ Yet fines also suffer from the inability to pay for harm and from the possibility that violators would escape public agency; Shavell, supra, note 41.

46 Ibid.

${ }^{47}$ S Rose-Ackerman, “Tort Law as a Regulatory System” (1991) 81 AEA Papers and Proceedings 2.

${ }^{48}$ P W Schmitz, "On the Joint Use of Liability and Safety Regulation" (2000) 20 International Review of Law and Economics 3, 371-382.
} 
where they showed that the judgment-proof problem's very existence seriously undermines the deterrence and insurance goals of tort law. Shavell notes that judgment-proof parties do not have the right incentive to either prevent accidents or purchase liability insurance. ${ }^{49}$ In other words, the judgment-proof problem is critical because if injurers are unable to pay in full for the harm they have caused their incentives to participate in risky activities will be greater than otherwise. Summers also shows that the judgment-proof injurers tend to take too little precaution under strict liability since accident costs are only partly internalised. ${ }^{50}$

Moreover, one should note that strict liability provides incentives for the optimal engagement in an activity if "parties' assets are enough to cover the harm they might cause, but their incentives will be inadequate if they are unable to pay for the harm". ${ }^{51}$ Further, Shavell (1986) argues that also under the negligence rule in situations where injurers are not induced to take optimal care (or there are errors in the determination of negligence) the "existence of the judgment-proof problem induces injurers to engage more frequently (sub-optimally) in the activity than they normally would" (Shavell, 1986). ${ }^{52}$

In addition, when injurers are for any reason unwilling to pay by virtue of complex assetownership-shifting arrangements put in place in advance of risky activity for all of the harm caused, this fact alone also distorts their incentive to make optimal precaution and damage mitigation decisions, including distorting or even completely eliminating any reason to purchase liability insurance. ${ }^{53}$ Namely, risk-averse injurers who may not be able to pay for all of the harm they cause will tend not to purchase full liability insurance or any at all. ${ }^{54}$ Here, Shavell notes that "the nature and consequences of this judgement-proof's effect depend on whether liability insurers have information about the risk and hence link premiums to that

\footnotetext{
49 J Summers, "The Case of the Disappearing Defendant: An Economic Analysis" (1983) 132 University of Pennsylvania Law Review, 145-185; and S Shavell, "The Judgement Proof Problem” (1986) 6 International Review of Law and Economics 1, 45-58.

${ }^{50}$ Summers, supra, note 49.

${ }^{51}$ Shavell, supra, note 49. Also see Ganuza and Gomez, supra, note 11.

${ }^{52}$ Shavell, supra, note 49, p 148.

${ }^{53}$ Shavell offers an example of the injurer's problem of choosing care $\mathrm{x}$ under strict liability, when his assets are $\mathrm{y}<\mathrm{h}$ and where the injurer's problem is formulated as minimising $\mathrm{x}+\mathrm{p}(\mathrm{x}) \mathrm{y}$; where the injurer chooses $\mathrm{x}(\mathrm{y})$ determined by $-\mathrm{p}^{\prime}(\mathrm{x}) \mathrm{y}=1$ instead of $-\mathrm{p}^{\prime}(\mathrm{x}) \mathrm{h}=1$, so that $\mathrm{x}(\mathrm{y})<\mathrm{x}^{*}$ (and the lower is $\mathrm{y}$, the lower is $\mathrm{x}(\mathrm{y})$ ). In this instance, the injurer's wealth after spending on care would be $y-x$, and only this amount would be left to be paid in a judgment; Shavell, supra note 49, p 148.

${ }^{54}$ G Huberman, D Mayers and C Smith, "Optimal Insurance Policy Indemnity Schedules” (1983) 14 Bell Journal of Economics 2, 415-426. Also see W R Keeton and E Kwerel, "Externalities in Automobile Insurance and the Underinsured Driver Problem" (1984) 27 Journal of Law and Economics 3, 149-179; and Shavell, supra, note 49 .
} 
risk". ${ }^{55}$ Consequently, "reduction in the purchase of liability insurance tends to undesirably increase incentives to engage in the harmful activity". ${ }^{56}$

De Geest and Dari-Mattiachi investigate the roles of punitive damages, negligence rules and potential under-compensation in instances of "pure probability technology" and convincingly show that average damages remedy is superior to punitive damages remedy. ${ }^{57}$ They also show that strict liability in such settings induces optimal precaution levels where one is dealing with high and intermediate asset thresholds but inefficient levels of precaution in all other settings. ${ }^{58}$

Others have extended the initial analysis of legal policy regarding liability insurance ${ }^{59}$ by providing the optimal conditions for the combined use of liability insurance ${ }^{60}$ and the minimum amount of assets needed to undertake a given activity. ${ }^{61}$ On the other hand, Pitchford explored extending the liability to lenders who contribute capital to activity that results in external harm and concluded that such an extension of liability is actually making accidents more probable. ${ }^{62}$ Hiriart and Martimort as well as Boyer and Porrini analysed the extension of liability in a principal-agent setting and suggested that extending liability to deep-pocket, related third parties might be beneficial. ${ }^{63}$

\footnotetext{
${ }^{55}$ Shavell, supra, note 39, p 180.

${ }^{56}$ In addition, the problem of excessive engagement in risky activities is mitigated to the extent that liability insurance is purchased; but the problem of suboptimal levels of care could be exacerbated if the insurers' ability to monitor care is imperfect; Shavell, ibid.

${ }^{57}$ G De Geest and G Dari-Mattiachi, "Judgment Proofness under Four Different Precaution Technologies"(2005) 161 Journal of Institutional and Theoretical Economics 1, 38-56.

${ }^{58}$ Ibid.

${ }^{59}$ P J Jost, "Limited Liability and the Requirement to Purchase Insurance" (1996) 16 International Review of Law and Economics 2, 259-276. Also see M Polborn, "Mandatory Insurance and the Judgement-proof Problem"(1998) 18 International Review of Law and Economics 2, 141-146.

${ }^{60}$ S Shavell, "On the Social Function and the Regulation of Liability Insurance" (2000) 25 Geneva papers on risk and insurance, Issues and Practice, 166-179.

${ }^{61}$ S Shavell, "Minimum Assets Requirements" (2002) Working paper, John M. Olin Center for Law and Economics and Business, Harvard Law School. Also see S Shavell, "Minimum Assets Requirement and Compulsory Liability Insurance as Solutions to the Judgement-proof Problem" (2004) Working paper, John M. Olin Center for Law and Economics, and Business, Harvard Law School.

${ }^{62}$ R Pitchford, "How Liable should a Lender be? The Case of Judgement-proof Firms and Environmental Risk" (1995) 85 American Economic Review, 1171-1186.

${ }^{63}$ Y Hiriart and D Martimort, "The Benefits of Extended Liability" (2003) Working Paper University of Toulouse; and M Boyer and D Porrini, "Modelling the Choice between Regulation and Liability in Terms of Social Welfare" (2004) 37 The Canadian Journal of Economics 3, 590-612.
} 


\section{Towards the optimal regulatory AI intervention: what can law and economics offer lawmakers?}

The previous discussion of the technical human-like features of super-intelligent AI and application of the main findings of the law and economics literature to super-intelligent AI suggests that today the law-maker faces the unprecedented challenge of simultaneously regulating possibly harmful and hazardous activity while not deterring innovation in the AI sector and associated industries. Yet, economically speaking, law is a much more resilient and robust mechanism than is often believed. ${ }^{64}$ Namely, old rules generally rely on strict liability in cases of new technologies and when there is no legitimate use ${ }^{65}$ the current laws and established legal mechanisms might, via such strict liability, provide a general, first-aid response to the potential problem of the dilution of incentives to reduce risk that arises when a person is completely indifferent to both the ex ante possibility of being found liable by the legal system for harm done to others and to potential accident liability (since the value of the expected sanction equals zero).

However, one may question whether the existing strict liability regimes are adequate to deal with the diluted incentives to reduce the risk associated with super-intelligent AI. For example, the literature emphasises that, legally speaking, in cases where damage is be caused by superintelligent AI it might prove impossible to identify the party responsible for providing compensation and then require such autonomous $\mathrm{AI}$ to somehow compensate for the damage it has caused. ${ }^{66}$ Namely, Directive $85 / 374 /$ EEC merely covers damage caused by a robot's manufacturing defects and provided the injured person can prove the actual damage, the defect in the product and the causal relationship between the damage and defect and thus strict liability or liability without fault may not be sufficient. ${ }^{67}$ The Directive also contains several defences (i.e. the non-existence of technical and scientific knowledge) and safe havens that might be used as liability defence mechanisms. Moreover, the strictly liable producer of the AI might

\footnotetext{
${ }^{64}$ Namely, since all new technology in essence presents a certain conceptual problem to the existing jurisprudence, efficient legal institutions react and generally address such issues by for example requiring legal standards of reasonableness, duty of care or good faith. See e.g. Guille v. Swan, Supreme Court of New York 1822; and Rylands v. Fletcher (1868) LR 3 HL 330.

${ }^{65}$ E.g. ballooning over Manhattan (Guille v. Swan, Supreme Court of New York 1822) or having a reservoir in very wet England (Rylands v. Fletcher (1868) LR 3 HL 330).

${ }^{66}$ See O J Erdelyi and J Goldsmith, "Regulating Artificial Intelligence: Proposal for a Global Solution" (2018) AIES , 95-101; A Breland, "Elon Musk: we Need to Regulate AI before it's too Late" (2017) The Hill; and V Wadhwa, "Laws and Ethics can't keep Pace with Technology" (2014) 15 Massachusetts Institute of Technology: Technology Review.

${ }^{67}$ Erdelyi and Goldsmith, ibid.
} 
itself, due to its size or limited assets, also be judgment proof. Yet, one should note that under the existing rules AI must already meet essential health and safety requirements ${ }^{68}$ and that efforts to produce European harmonised standards for AI are ongoing. ${ }^{69}$

The mentioned shortcomings of the strict liability regime suggest that what is best in such instances is not to use the liability-related ex post tort law system but to rely on ex ante regulatory intervention instead. Thus, the classic debate on the two different means of controlling hazardous activities, namely ex post liability for harm done or ex ante safety regulation may, due to the shortcomings of human-centred, liability-related tort law instruments, boil down to a question of efficient ex ante regulation. ${ }^{70}$

4.1 In principle, product liability already exists as the optimal remedy for non-autonomous AI: no need for legislative innovation

Generally, the non-autonomous, non-superhuman AI revolution is not a problem for the established legal concepts. Namely, when legal systems face a risk-related new technology they address its potential hazards and illegitimate uses by imposing strict (product) liability. Such liability then serves as a deterrence mechanism aimed at mitigating potential risks and hazards.

Yet, as Turner notes, the current systems of strict liability in the EU and the USA are subject to several defences (safe heavens) which may prove overly permissive when applied to those who make super-intelligent AI. ${ }^{71}$ Obviously, the producers of super-intelligent AI devices can take advantage of such non-liability-safe-heavens, thereby undermining the overall effectiveness of the liability-related incentive system. Still, the current product-liability regimes are adequate for dealing with the harm and risk caused by non-autonomous AI but might be inadequate for addressing the possible risks brought by super-intelligent AI

\footnotetext{
${ }^{68}$ See e.g. Directive EC 2006/42 on machinery; Directive 2014/53/EU on radio equipment; Directive 2001/95/EC on general product safety.

${ }^{69}$ EU Commission, COM (2018) 237 final.

${ }^{70}$ P Schmitz, "On the Joint Use of Liability and Safety Regulation" (2000) 20 International Review of Law and Economics 3, 371-382.

${ }^{71}$ J Turner, Robot Rules: Regulating Artificial Intelligence (Palgrave Macmillan 2019). See also Y Wilks, Artificial Intelligence: Modern Magic or Dangerous Future? (Icon Books 2019).
} 


\subsection{The super-intelligent AI judgment-proof problem}

Both the new industrial revolution and the technical features of super-intelligent AI analytically imply that super-intelligent AI and the related liability discussion should be seen as a potential judgment-proof problem. Namely, as already shown, the classic law and economics concept of the judgment-poof problem informs that if injurers lack sufficient assets to pay for the damage they cause their incentives to reduce risk will be inadequate. ${ }^{72}$ Yet, the judgment-proof problem could also be defined much more broadly to include the problem of the dilution of incentives to lower risk that emerge when a person is completely indifferent to both the ex ante possibility of being found legally liable for harm done to others and potential accident liability (given that the value of the expected sanction equals zero). This paper employs a broad definition of the judgment-proof problem which encompasses all potential sources of the dilution of incentives to mitigate risk and not merely the narrower inability of a tortfeasor's to pay damages. In other words, super-intelligent AI might be completely indifferent to the ex ante possibility of being found liable by the human-imposed legal system for harm caused, and hence its incentives to engage in risky activities will be inadequate. Thus, the judgment-proof characteristics of superintelligent AI could in fact wholly undermine the deterrence and insurance goals of tort law. Namely, the evolution of super-intelligent and super-human AI and its capacity to develop characteristics and even personhood ${ }^{73}$ in a manner never envisaged by its designer or producer undermines the effectiveness of the traditional strict liability and other tort law instruments.

The judgment-proof characteristic of a super-intelligent AI system also implies that AI's activity levels will tend to be socially excessive and will contribute to excessive risk taking by the super-intelligent $\mathrm{AI} .{ }^{74}$ It will have no liability-related incentive to mitigate risk and its incentives to reduce the risk and harm will be completely diluted. The deterrence goal might be corrupted irrespective of the liability rule since the judgment-proof super-intelligent AI (possessing autonomous 'personhood' and in control of its own decision-making processes) will simply not internalise the costs of any accident it might cause. ${ }^{75}$ Hence, as the literature suggests, no kind of tortious liability will provide adequate incentives to alleviate the risk (and

\footnotetext{
${ }^{72}$ Shavell , supra, note 49, p 58.

${ }^{73}$ Consequently, it may also generate completely unexpected harmful consequences.

${ }^{74}$ See S Shavell, Foundations of Economic Analysis of Law (Harvard University Press 2004) 175-289; R Pitchford, "Judgement-proofness" in P Newman (ed.), The New Palgrave Dictionary of Economics and the Law (Macmillan, 1998), p 380-383; and A H Ringleb, and S N Wiggins, "Liability and Large-Scale, Long-Term, Hazards" (1990) 98 Journal of Political Economy 3, 574-595.

75 This implies that courts will be unable to collect damages from an autonomous AI or, for example, sentence it to imprisonment.
} 
there will be no incentives or a technical basis for AI to purchase insurance). In other words, the insurance goal will be undermined to the extent that the judgment-proof tortfeasor (autonomous AI of any kind) proves unable to fully compensate its victims. Moreover, as shown by Logue, first-party insurance markets will also not provide an adequate response/remedy. ${ }^{76}$

\subsection{Policy suggestions regarding judgment-proof super-intelligent AI}

Law and economics literatures offer several potential types of policy responses to mitigate the identified judgment-proof characteristics of autonomous AI and its continuous, unpredictable change once it leaves the production line and the potential resulting hazards.

The first instrument is vicarious liability. ${ }^{77}$ Shavell, for example, suggests that if another party (principal) has some control over the behaviour of the party whose assets are limited (agent), the principal can be held vicariously liable for the losses caused by the agent. ${ }^{78}$ Hence, vicarious liability (indirect reduction of risk) and a specific principal-agent relationship between the owner (a human who uses AI) and their autonomous AI agent should be introduced. The principal (owner) should be held vicariously liable for the losses the agent (autonomous AI) causes. If the principal can observe the agent's level of care the imposition of vicarious liability will induce the principal to compel the agent to exercise optimal care. In other words, an extension of liability should indirectly lead to a reduction of risk.

Yet, if the principal is unable to observe and control the level of care exercised by the agent (AI) the lead he will generally be unable to compel the agent. ${ }^{79}$ Still, if the principal can control the AI's level of activity (but has no observation capacity) then such vicarious liability will induce the principal to reduce the AI's participation in risky activity.

However, what if AI is truly autonomous, capable of self-learning, developing emergent properties and adapting its behaviour/actions to the environment while even being self-aware?

\footnotetext{
${ }^{76}$ K D Logue, "Solving the Judgement-proof Problem" (1994) 72 Texas Law Review, 1375-1394.

${ }^{77}$ For a synthesis, see A Sykes, "The Economics of Vicarious Liability" (1984) 93 Yale Law Journal, 168-206; and R H Kraakman, "Vicarious and Corporate Civil Liability" in G De Geest and B Bouckaert (eds.), Encyclopedia of Law and Economics (Volume II. Civil Law and Economics, Edward Elgar 2000). ${ }^{78}$ Shavell, supra note 49. Also see S Shavell, Economic Analysis of Accident Law (Harvard University Press 1987).

${ }^{79}$ S Shavell, Foundations of Economic Analysis of Law (Harvard University Press 2004) 180 et seq.
} 
In these circumstances, the imposition of vicarious liability might prove completely inadequate due to the extreme judgment-poof problem. Here, law and economics suggests the introduction of a whole arsenal of economic/legal institutions that might address such an extreme superintelligent AI-judgment-proof problem.

Law and economics literature proposes the following instruments: a) requiring the principal to have a certain asset minimum to engage in an activity; b) the compulsory purchase of liability insurance coverage (for the principal); c) direct ex ante regulation of AI's risk-creating behaviour - a regulatory agency setting standards for behaviour/employment/operating/functioning ${ }^{80}$ d) safety standards (which alone are inadequate ${ }^{81}$ ) and registration (of both the principal and the agent); e) the principal's criminal liability ${ }^{82} \mathrm{f}$ ) extending liability from the actual injurer (AI) to the company - by piercing the veil of incorporation; g) corrective taxes equal to the expected harm; and h) establishing a wide insurance fund that is publicly and privately financed.

In addition, one should consider introducing the AI manufacturer's strict liability supplemented by the requirement that an unexcused violation of a statutory safety standard is negligence per se. Moreover, compliance with the regulation standard should not relieve the injurer's principal from tort liability. Thus, the rule per se (violation of a regulatory standard implies tort liability - including strict liability) should also be applied to AI-related torts and the compliance defence of an AI manufacturer or its principal should not be accepted as an excuse.

This paper also suggests that regulation and tort law should be applied at the same time. Ex post liability and ex ante regulation (safety standards) are generally viewed as substitutes for correcting externalities where the usual recommendation is to employ that policy which produces lower administrative costs. However, Schmitz shows that the joint use of liability and regulation can enhance social wealth. ${ }^{83}$ Namely, regulation removes problems that affect liability while liability limits the cost of regulation. ${ }^{84}$ General regulatory standards should settle

\footnotetext{
${ }^{80}$ Shavell points out that such direct regulation - safety standards - will help to form incentives for the principals and the manufacturer to ex ante reduce risk as a precondition for engaging in an activity; Shavell, ibid.

${ }^{81}$ Namely, autonomous AI might still have an excessive incentive to engage in risky activity since such ex ante safety regulation does not impose on AI the losses expected to be caused by its activity

82 Namely, since AI is completely judgment-proof, criminal liability should be imposed on the principal.

83 Schmitz, supra, note 70.

${ }^{84}$ S Rose-Ackerman, "Regulation and the Law of Torts" (1991) 81 American Economic Review, 54-58.
} 
at a lower level of care (lower than optimal) and be combined with tort law instruments. ${ }^{85}$ That is, by introducing an ex ante regulatory standard the principal and the agent (AI) might be prevented from taking low levels of precaution and might find it convenient with the regulatory standard despite the judgment-proof problem.

Moreover, the informed lawmaker should combine strict liability and vicarious liability the strict liability of the manufacturer and vicarious liability of the principal (principal as either a legal or physical person). Yet, since the product liability regime assumes that a product does not continue to change in any unpredictable way once it leaves the production line, such a combination might not be sufficient. Furthermore, the producers (companies) and designers of super-intelligent AI devices might be judgment proof due to their size and lack of assets. ${ }^{86}$ The classic debate on the two different approaches to controlling hazardous activities, namely $e x$ post liability for harm done and ex ante safety regulation may, given the mentioned shortcomings, boil down to a question of efficient regulatory timing and ex ante regulation. The identified judgment-proofness of super-intelligent AI is seeing society effectively shift back to regulation. Thus, a specific EU regulatory intervention is suggested that encompasses the following: a) the requirement that a principal has certain minimum assets to engage in an activity; b) the compulsory purchase of liability insurance coverage (for the principal); c) direct ex ante regulation of AI's risk-creating behaviour - an EU regulatory agency setting standards for behaviour/employment/operating/functioning; d) safety standards; e) compulsory registration in super-intelligent-AI- related registries; f) the principal's criminal liability; g) extending liability from the actual injurer (AI) to the company that either uses or produces the $\mathrm{AI}$ - piercing the veil of incorporation; h) corrective taxes that equal the expected harm; and i) the establishment of an EU-wide publicly/privately-financed insurance fund.

Such ex ante regulatory activity is also in line with the theory of optimal legislative timing. In a ground-breaking paper, Gersen and Posner investigated the optimal timing of legislative action and noted that decisions on the timing of legal intervention are often as important as decisions on the content of a new law. ${ }^{87}$ They argue that lawmakers cannot know with certainty what the appropriate law will be in the future and therefore cannot know with the certainty

\footnotetext{
${ }^{85}$ G De Geest and G Dari-Mattiacci, "Soft Regulators, Tough Judges" (2007) 15 Supreme Court Economic Review 2, 119-140.

${ }^{86}$ If one then employs the 'let the machine learn' concept, the argument that a designer should have foreseen the risk becomes harder to sustain.

87 J E Gersen and E A Posner, "Timing Rules and Legal Institutions" (2007) 121 Harvard Law Review 2, 543589.
} 
what the future stream of benefits from the law will be. ${ }^{88}$ In addition, the costs of introducing the new law are largely sunk and irreversible (e.g. the outlay of resources to formulate and enforce the law) where the costs of implementing the new law cannot be recovered if the law turns out to be inappropriate. Timing of the investment becomes a critical issue for such irreversible investments. ${ }^{89}$ In economic terms, the lawmaker's decision to invest in the new law represents 'opportunity costs' of abandoning the option to implement the law in the future.

However, there is also an 'opportunity benefit' of investing today. Parisi and Ghei offer a formal model that determines three attributes that law-making shares with investment: a) the costs of law-making cannot typically be recovered if the rule proves to be ineffective or undesirable at a later point in time; b) the future benefits of the legislation are uncertain; and c) lawmakers have the option to postpone changing the current legal rules. ${ }^{90}$ The literature also offers the concept of the optimal time to legislate whereby a benevolent and rational lawmaker should enact a new rule (or modify an existing one) when the present value of the expected benefits from the legal innovation is at least equivalent to its costs. ${ }^{91}$ Obviously, the optimal timing of law-making is affected by the presence of uncertainty since, once uncertainty arises, the desirability of the law changes accordingly. Gersen and Posner investigate several potential timing rules and emphasise the significance of the 'anticipatory legislation' rule. ${ }^{92}$ Thus, the legislation will only become effective if its effects are positive and such a timing rule offers the option of exit through repeal. ${ }^{93}$

Moreover, such anticipatory legislation entails lower adjustment costs since stakeholders can more confidently rely on the public good being created - i.e. such legislation increases the likelihood that the public good will be created. ${ }^{94}$ The optimal timing of the legal intervention is thus crucial because delays in law-making decisions may come at a cost. The exponential rise of super-intelligent AI technology over time is adding to the costs of law-making and in

\footnotetext{
88 Ibid.

${ }^{89}$ Ibid. Also see B Luppi and F Parisi, "Optimal Timing of Legal Intervention: The Role of Timing Rules" (2009) 122 Harvard Law Review 2, 18-31.

${ }^{90}$ F Parisi and N Ghei, "Legislative Today or Wait until Tomorrow? An Investment Approach to Lawmaking" in F Caffagi, A Nicita and U Pagano (eds), Legal Orderings and Economics Institutions (Routledge 2007).

${ }^{91}$ R S Pyndck, "Irreversibility, Uncertainty and Investment" (1991) 29 Journal of Economic Literature 3, 11101148. Also see Parisi and Ghei, ibid.

${ }^{92}$ Under this option, the law is enacted at time $\mathrm{t}=1$ (imposing certain enactment costs $\mathrm{k}$ ), to take effect in period $\mathrm{t}=2$ and such timing allows the lawmaker to repeal the statue if information obtained in the first period shows that the enactment is inefficient; Gersen and Posner, supra note 109.

${ }^{93}$ Such anticipatory legislation has an advantage over with immediate legislation or deferred legislation since the legislative costs are incurred more in period $t=1$ than in period $t=2$ where such costs might be much higher; Gersen and Posner, supra, note 87.

${ }^{94}$ Gersen and Posner, supra, note 87.
} 
the future such costs may, taking the precautionary principle into account, become even higher. Thus, specific Europe-wide regulatory activity should employ the 'anticipatory legislation' approach due to the specific features of super-intelligent AI in line with the theory on the optimal timing of legal intervention. Hence, as stressed, a specific EU-wide regulatory anticipatory regulatory intervention is suggested that encompasses the direct ex ante regulation of AI's risk-creating behaviour (an EU regulatory agency setting standards for behaviour/employment/operating/functioning), requires principals to hold certain minimum assets if they are to engage in an activity, the compulsory purchase of liability insurance coverage, safety standards and Turing Registries, the principal's criminal liability, extended liability from the actual injurer (AI) to the company by piercing the veil of incorporation, corrective taxes that equal the expected harm, and the establishment of an EU-wide insurance fund with public/-private backing.

4.4 A new special electronic legal person should not be created

Regarding the specific legal status, in paragraph 59 of its Resolution on Civil Law Rules in Robotics ${ }^{95}$ the EU Parliament suggests that the EU create a specific legal status for robots so that at least the most sophisticated autonomous robots can be established as having the status of electronic persons responsible for making good any damage they may cause, and possibly applying an electronic personality to cases where robots (AI) make autonomous decisions or otherwise interact with third parties independently. Moreover, Solum, ${ }^{96}$ Wright, ${ }^{97}$ Teubner ${ }^{98}$ and Koops et al. also argue that AI should be given a legal personality and that there is no compelling reason to restrict the attribution of action exclusively to humans and social systems. ${ }^{99}$ Furthermore, Allen and Widdison state that when an item of AI is capable of developing its own strategy it makes sense that the AI should be held responsible for its independent actions. ${ }^{100}$ Yet, it must be emphasised that Teubner, for example, suggests that

\footnotetext{
95 P8_TA (2017) 0051.

${ }^{96}$ L B Solum, "Legal Personhood for Artificial Intelligences" (1992) 70 North Carolina Law Review, 1231.

${ }^{97}$ G R Wright, "The Pale Cast of Thought: On the Legal Status of Sophisticated Androids" (2001) 25 Legal Studies Forum, 297.

${ }^{98}$ G Teubner, "Rights of Non-humans? Electronic Agents and Animals as New Actors in Politics and Law" (2007) Lecture delivered on 17 January 2007, Max Weber Lecture Series MWP 2007/04. Also see Teubner, supra, note 5 .

${ }^{99}$ B J Koops, M Hildebrandt and D O Jaquet-Chiffell, "Bridging the Accountability Gap: Rights for New Entities in the Information Society?” (2010) 11 Minnesota Journal of Law, Science \& Technology 2, $497-561$. ${ }^{100}$ Allen Tom and Robin Widdison, "Can computers make contracts?", 9 Harvard Journal of Law \& Technology, 1996.
} 
software agents should be given a carefully calibrated legal status. ${ }^{101}$ The answer to the risk brought by autonomy would, according to Teubner, be their status as actants, as actors with partial legal personhood whose autonomous decisions are made legally binding and in case they trigger liability for damages. ${ }^{102}$ Are such suggestions supported by the insights from law and economics?

Obviously, from a law and economics perspective the establishment of a special status of electronic person for super-intelligent AI that would have its own legal personality and responsibility for potential damages should be avoided. ${ }^{103}$ Namely, under such proposal the super-intelligent AI itself would be legally responsible for damage, rather than its principal, owner or manufacturer. This would then also imply that super-intelligent AI agents own financial assets and are subject to sanctions if they do not comply. As this paper argues, at best this does not make any sense and, at worst, it might bring dire consequences.

Namely, the identified judgment-proofness of super-intelligent AI suggests that the establishment of such a legal personality would, while amplifying the judgment-proof problem, have unexpected adverse effects. Why would super-intelligent AI with an electronic legal personality care at all if it were imprisoned or sanctioned for non-payment or causing harm? The judgment-proof problem would actually dilute the incentives of the super-intelligent AI (even though - or even because - it has a legal electronic personality) to reduce risk that arises due to the AI's complete indifference to both the ex ante possibility of being found legally liable for harm done to others and potential accident liability (where the value of the expected sanction equals zero). Moreover, establishing a specific electronic legal personality for superintelligent AI would imply that policymakers then rely on the existing tort law system to control activities that create risks of harm and induce the optimal amount of precaution. Yet, as shown, the judgment-proofness of super-intelligent AI would undermine the essential deterrence and insurance goals of tort law, leaving potential risks unaddressed. In other words, the

\footnotetext{
101 Teubner, supra, note 5 .

102 Teubner states that "in response to the identified risks, the law should carefully calibrate the legal status of algorithms based on their concrete role. For the autonomy risk, it is an adequate answer to grant software agents the status of partial legal personhood (their autonomous decisions should be legally binding and should give rise to liability consequences). This gives them the limited legal subjectivity to conclude binding contracts for others as a proxy. At the same time, in cases of contractual and non-contractual liability, they are to be recognized as legally capable assistants, so that the machine misconduct itself (and not merely the conduct of the companies behind it) constitutes a breach of duty for which the companies must be held responsible". Ibid.

${ }^{103}$ However, one might argue that a specific principal-agent legal relationship could be introduced between the owner (the human who employs the AI) and their autonomous AI agent.
} 
establishment of such a specific electronic person might institutionalise the judgmentproofness of super-intelligent AI.

Accordingly, the establishment of an unregulated human-like electronic personality is not an effective or adequate response to the identified super-intelligent-AI- judgment-proofness, but might be seen as an amplifier making the problem even more persistent. Namely, granting a special electronic legal personality to super-intelligent AI would make liability-related legal regimes completely ineffective. Consequently, granting legal personality to super-intelligent AI might open Pandora's box of moral hazard and create perverse incentives on the side of human principals, the AI industry, designers, users, owners and will exacerbate the judgmentproof problem of a super-intelligent AI device.

\section{Conclusions}

This paper sought to address the role of public regulatory policy in regulating superintelligent AI, the related risk and civil liability for damage caused by such super-human AI. The main findings are: a) the current law-making anticipatory activities and initiatives are in line with the theory of the optimal timing of legislative action; b) generally speaking, the existing laws and legal mechanisms adequately address the responsibility for non-autonomous $\mathrm{AI}$; b) if super-intelligent AI evolves unpredictably once it leaves the creator's lab then ex ante regulatory intervention is suggested; c) the classic debate on the two different approaches to controlling hazardous activities, namely ex post liability for harm done and ex ante safety regulation, boils down to a question of efficient ex ante regulation; d) super-intelligent AI and associated companies might be judgment proof; e) a specific regulatory intervention is suggested to tackle the potential judgment-proof characteristic of super-intelligent AI which encompasses the requirement for the principal to have certain minimum assets to engage in an activity, the compulsory purchase of liability insurance coverage (for the principal), anticipatory regulation of AI's risk-creating behaviour - a regulatory agency setting standards for behaviour/employment/operating/functioning, safety standards and registries, the

principal's criminal liability, extending liability from the actual injurer (super-intelligent AI) to the company by piercing the veil of incorporation, corrective taxes that equal the expected harm, and the setting up of a wide insurance fund that relies on public/private financing. Moreover, the contemplated new special electronic legal personality for super-intelligent AI 
should not be introduced. As this paper attempts to show, the judgment-proofness of superintelligent AI implies that any establishment of a legal personality would, while exacerbating the judgment-proof problem, bring unexpected adverse effects. It would dilute the incentives of super-intelligent AI to reduce the risk that materialises due its complete indifference to both the ex ante possibility of being found liable by the legal system for harm done to others and potential accident liability. The paper also shows that, due to identified shortcomings, the debate on the different ways of controlling hazardous activities may be reduced to a question of efficient ex ante safety regulation. In other words, regulatory intervention is from the law and economics perspective, due to the identified shortcomings of the current tort law institutions the best option to govern the super-intelligent AI systems.

\section{Footnotes}

The author would like to thank Roger van den Bergh, Gerrit De Geest, Ben Depoorter, Matthew Dyson, Michael Faure, Paula Giliker, Paul Heald, Eric Helland, Jonathan Klick, Anne Lafarre, Alain Marciano, Philip Morgan, Jens Prüfer, Giovanni Ramello, Wolf-Georg Ringe, HansBernd Schäfer, Ann-Sophie Vandenberghe, Bruce Wardhaugh, the participants of the IMA Workshop, University of York, 2020, the workshop session at the European Master in Law and Economics (EMLE) Midterm Meeting, Hamburg, 2019, the 110th Society of Legal Scholars Annual Conference at the University of Central Lancashire, Preston, 2019 and the participants of the AGCOM workshop on "Law and economics of big data and artificial intelligence", Rome, 2018 for their thoughtful comments, suggestions and advice. Funding received from: Slovenian Research Agency (Javna Agencija za Raziskovalno dejavnost Republike Slovenije, ARRS); name of the research project: Challenges of inclusive sustainable development in the predominant paradigm of economic and business sciences, grant no.: P5-0128. 